\title{
Research on energy recycle percentage of servo motor
}

\author{
Yen-Ming Tseng ${ }^{1}$, Li-Shan Chen ${ }^{2,}{ }^{*}$, Jeng-Shyang $\operatorname{Pan}^{3}$, and Jing Huang ${ }^{4}$ \\ 1,3 Key Laboratory of Big Data Mining and Application/School of Information Science and Engineering, Fujian University of \\ Technology, Fuzhou City, 350118, Fujian, China \\ ${ }^{2}$ School of Management, Fujian University of Technology, Minhou, Fuzhou City, 350118, Fujian, China \\ ${ }^{4}$ School of Information Science and Engineering, Fujian University of Technology, Fuzhou City, 350118, Fujian, China
}

\begin{abstract}
The energy recycle circuit fed back the energy to batteries is one of the important means to extend the travel distance of action vehicle for an electric vehicle or hybrid vehicle by driven batteries. In order to achieve energy recycle must be use, such as the motor characteristics, the principle of motor controller and design of circuit to reach the energy recycle of motor in action vehicles. Focus on the $24 \mathrm{~V} 8 \mathrm{~A}$ $150 \mathrm{~W}$ servo motor and its shaft coupling with a condition by magnetic brake to simulate as the analog load and adjust the brake to 0.2 Newton-meter. According to the characteristics of the motor, the principle of the motor controller and the design and energy recovery of the circuit system for discussion, that include drive control circuit of motor and based on the former to design the circuit of energy recycle circuit of motor and to feed back the energy to the driving batteries. According to the characteristics of the motor, the principle of the motor controller and the design and energy recovery of the circuit system for discussion, that include drive control circuit of motor and based on the former to design the circuit of energy recycle circuit of motor and to feed back the energy to the driving batteries. By mean of the architecture of energy recycle circuit to test the power recovery which divide into without load and without energy collector, without load and with energy collector, with load and without energy collector and with load and energy collector four cases under these conditions to investigate the power recovery analysis. For the statistics of energy, the average energy recovery power percentage by without load and without energy collector is $9.7 \%$, the average energy recovery power percentage by without load and with energy collector is $20.5 \%$, the average energy recovery power percentage by with load and without energy collector is $1.82 \%$, and the average energy recovery power percentage by with load and with energy collector is $3.1 \%$.
\end{abstract}

\section{Introduction}

From Electricity power source transfer to Electromagnetic energy and Mechanical movement is factions of motors that is already exist in daily life of and in industrial factories as well as active traffic vehicles. Braking or deceleration in the operation or rotation status of the motor, but which can produce energy or called electricity power by this operation and to transfer another form that called heat to diverge to air. It is mean to waste the energy that made low effective and not useful well. And form the view of useful, it can to collect this energy to energy collector or and storage reuse or feedback to source of force. In recent years, the relevant literature and this article are closely related to the following: (1) Energy storage for the interface of energy recovery $[1,2]$. (2) Energy recovery using super capacitors and neural networks [3, 4]. (3) Electric vehicle in driving torque and braking energy feedback charge control [5]. (4) In the train on the automatic driving when the gearshift and brake cause slow down status made the momentum transfer electricity type to the power regeneration of energy management system [6,7]. (5) Using of ultracapacitance with experimental characteristics for the regulating voltage and providing the inrush current to improve the driving torque of motor [8]. (6) Used in the train on the automatic driving and braking to energy recycle to DC/AC power system [9, 10]. Design and implementing considerations of a novel rapid charger for lead-acid batteries are using a single-stage power converter with an energy recovery cell [11]. In this paper, that focus at the servo motor and the specification is DC24V, 8A, 150W; 1350RPM which base on the load characteristics of motor, the principle of the motor controller of the circuit system and to reach the energy recycle by designing recovery circuit. Any motor is controlled by the drive circuit to control the speed, torque and power of motor which by modifying the motor control drive circuit without changing its drive system architecture that to design control recovery circuit system and calculate the energy recovery power at specific stage. Because the choice of motor size and power, are more suitable for small appliances and children's electric vehicles, such as the use of a wide range of applications,

${ }^{*}$ Corresponding author: sun56@ms8.hinet.net 
so as the energy recovery power and the motor itself to compare the characteristics of the selected motor specifications both of no load and loaded energy recycling statistics. How to use the energy generated by the principal of generator as a research goal, and can be used for electric vehicles and electric bicycles to develop applications. It is to study on the architecture of drive and control circuits and according to the characteristics of the motor speed control and power generation by motor speed, the possess the energy collector or not is chosen to design the structure of the control energy recycle circuit system, furthermore, actual measurement of the recycling voltage, current and power of the motor energy recovery. The energy recovery power in different environments or different types of motors is different.

\section{Design the energy recycle of motor}

\subsection{Structure of the energy recycles of motor}

When brakes is active and the inertia movement of the electric vehicle in the driving mode that controller will cut off the power supply let the batteries no more output to drive the motor but in this case, the motor is converted the effect motor to generator made lots of electricity or energy to support the energy recycle, if not support the architecture to energy recycle that electricity or energy will consumption become waste in lines. The role change from motor to generator that produce the electricity or energy and store in energy collector or storage to regular the voltage via DC to DC boost feedback to batteries to complete the function of energy recycle and achieve the benefits. Fig. 1 is the motor energy recovery process block diagram by battery which is the energy source and through the controller to drive the motor for speed or torque control, at the same time the motor deceleration of speed and cut off the supply power but based on the inertia law the motor still reverse and the magnetic field over cross the coil to produce the electricity made the motor become generator. Due to the electricity output by motor which not stable and the waveform like lighting in very short time interval appear to catch and regulate voltage in energy storage. It is through the chargeback controller to step up voltage and energy feedback. The main function can be let the wasted to recycle to source become a part of the power source that can improve the battery efficiency and extended the endurance.

\subsection{The current flow of the motor in the energy recycles}

Such as the motor operate in multi-quadrant and base on the equivalent circuit that current flow can decide the mode of motor. When the braking is active and the terminal voltage polarity of reminding unchanged and the motor reverse direction at the same status that only one parameter such as direction of current flow in contrast between in motor mode and generator mode. As shown in Fig. 2 in general motor mode which current $I m$ and path for solid line. When the brake active that breaking control make the switch box change the function of controller to cut off the power and he motor function into a generator and with the controller anti-current, energy recovery $I c$ path for the dotted line feedback to the battery.

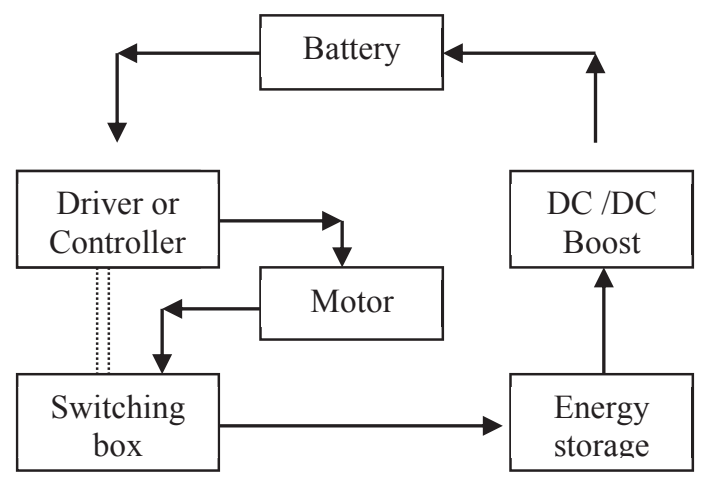

Fig.1. Motor energy recovery process block diagram.

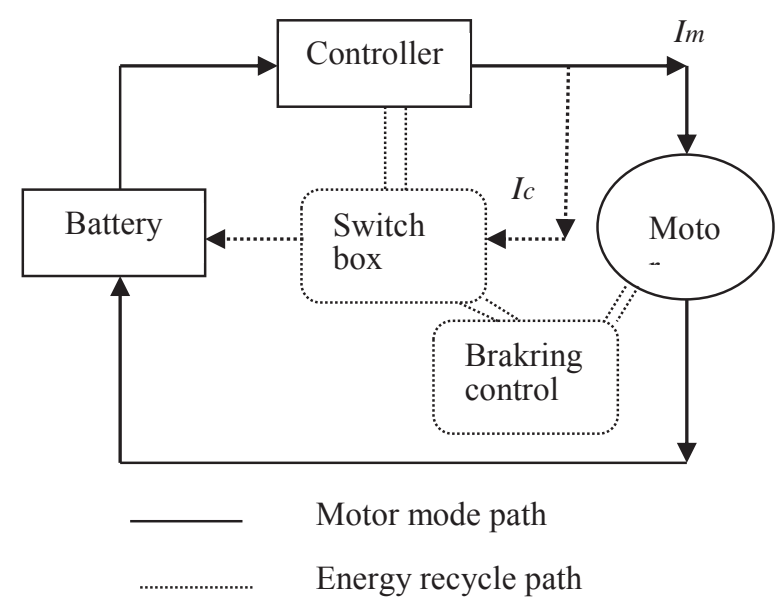

Fig.2. Energy recovery control diagram.

The motor is divided into both modes, one for drives the vehicle in motor mode and another for energy recycle for generator mode. According to equivalent circuit of motor analysis which without change the structure of the motor it is only need to change the input and output energy. As shown in Fig. 3, the equivalent circuit and current of the motor flow diagram. When used for the motor which $V$ in for the power input polarity and $T$ for the mechanical torque output direction as shown in the current direction for the figure is the same direction and the motor for the power consumption.

When used as a generator which $V$ in for the power input polarity and $T$ for the mechanical torque output direction is the same as the motor mode, $V$ in for the power output that the current direction is the opposite direction and the generator for the power supply. In the direction of the generator and the motor current will be a difference of 180 degrees, which is the most important point of energy recovery point of view, the general energy recovery to DC permanent magnet motor recovery more than then onpermanent magnet motor. 


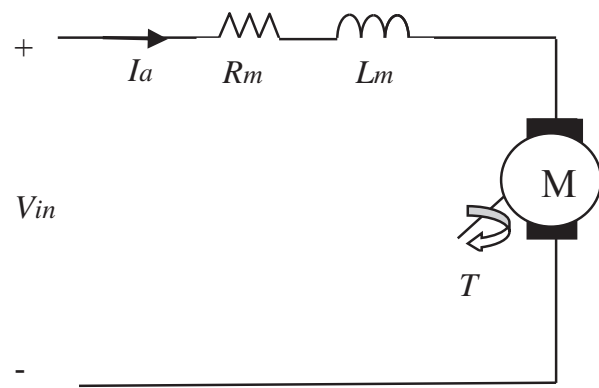

$R m$ : internal resistance of motor $\mathrm{Lm}$ : Self inductance of motor

Fig.3. Equivalent circuit and current flow diagram of motor.

\subsection{Pulse width modulation (PWM) control drive circuit}

By using the servo motor as the research object to design a simple pulse width modulation(PWM) technology to drive the circuit and regulate the voltage and current feed in the motor and base on the voltage changing and current changing at the same time to varying the input power to drive the motor such as Fig. 4.

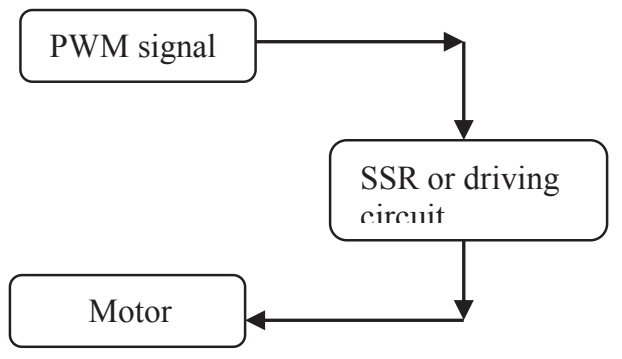

Fig.4. Motor speed control by PWM.

The period $T=1 / f$ is also fixed by the signal $\mathrm{f}$ which is set by the PWM controller to output and the period $T=$ drive controller on time $(T o n)+$ drive controller cut off time (Toff), As shown in Fig. 5. By changing the Ton and Toff time to change SSR conduction status and time, in other words, that determines the input power into the motor time and changing the voltage across the motor.

General DC motor relationship between speed and voltage as show in equation (1), when $K \Phi$ fixed, the voltage and speed is proportional. The torque of motor is based on the formula (2), when $K^{\prime} \Phi$ fixed, the current is proportional to the torque.

In general, when the voltage changes made the current also changes and reflecting the motor speed and torque also will change.

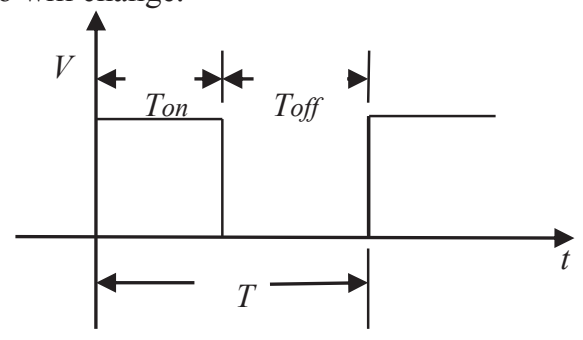

Fig.5. PWM conduction signal.
$E=K \Phi N$

$T=K^{\prime} \Phi I a$

where

$E$ : Terminal voltage of motor

$K$ : Voltage coefficient

$\Phi$ : Magnetic flux

$N$ : Rotating speed

$T$ : Torque of motor

$K^{\prime}$ : troque coefficient

Ia: Armature current

\section{Measurement and analysis of motor energy recycle}

In order to understand the energy recovery different that divide into four cases to discuss, one for without load and without energy collector, two for without load and with energy collector, three for with load and without energy collector, and the final case for with load and with energy collector to compare the difference.

\subsection{Energy recovery waveform}

Fig. 6 shows the servo motor in energy recovery status which voltage, current and recovery power waveform. It is clear that the recovered voltage curve and the current curve are in the relationship between the time period as the abscissa, in which the voltage curve approaches the linear and slightly declining trend and closely related to the length of the time period. Because the circuit design has a boost circuit, the voltage boost to the battery voltage higher than the back after the rechargeable battery, because the chargeback voltage is higher than the battery voltage and will be charged to power. The current curve with the wave form of the waveform, because the booster has a minimum voltage to a level before the booster can only boost before the charge. The voltage of the discharge voltage and the current has a pulse wave shape, and the voltage has a decreasing trend. The maximum value of the boost voltage and the maximum current and the instantaneous effective power are shown in the figure. The chargeback period depends on the current waveform till the current to zero that mean no energy back to charge to battery which no matter with the voltage.

Fig. 6 shows the maximum voltage of energy recycle status is $28.8 \mathrm{~V}$, the maximum current value is $463 \mathrm{~mA}$ of the energy back to the battery and the power of the battery back to the battery is $192 \mathrm{~mW}$.

\subsection{Energy recovery of servo motor}

In the servo motor energy recovery situation, (1) without load and without energy collector that energy recycling curve as voltage, current and power as Fig. 7, (2) without load and with energy collector that energy recycling curve as voltage, current and power as Fig. 8, (3) with load and without energy collector that energy recycling curve as voltage, current and power as Fig. 9, and (4) with load and with energy collector that energy recycling curve as 
voltage, current and power as Fig. 10. Comparison of these four conditions to discuss the curve of the trend in the case of no load voltage curve is smoother, the voltage is proportional to the motor speed, and the current curve is irregular. In the case of loaded current curve is more smooth and fixed, the voltage curve is irregular.

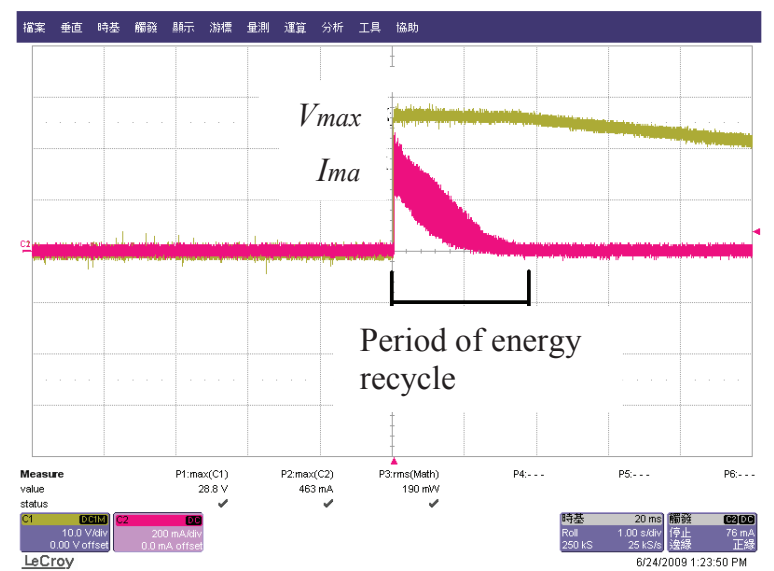

Fig.6. Voltage and current curve of Servo motor energy recycle

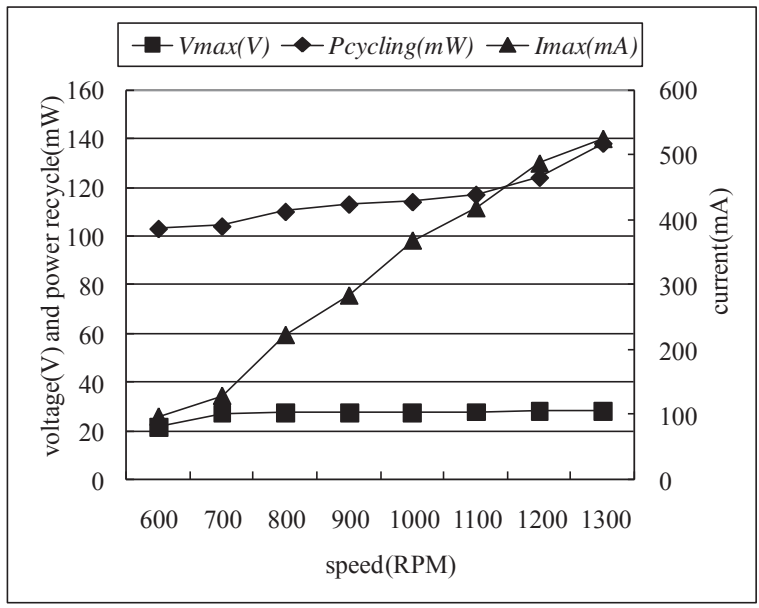

Fig.7. Energy recycle curve of without load and without energy collector of servo motor.

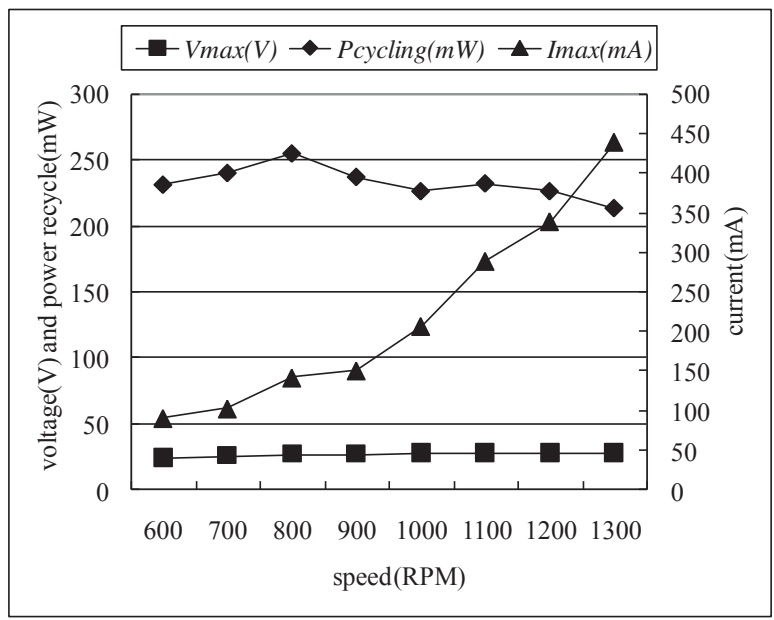

Fig.8. Energy recycle curve of without load and with energy collector of servo motor.

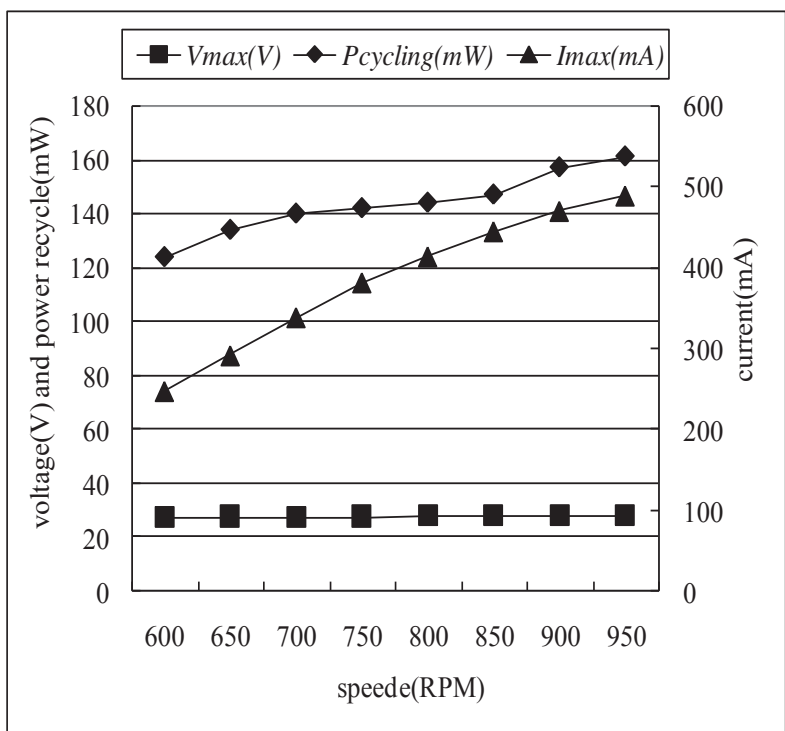

Fig.9. Energy recycle curve of with load and without energy collector of servo motor.

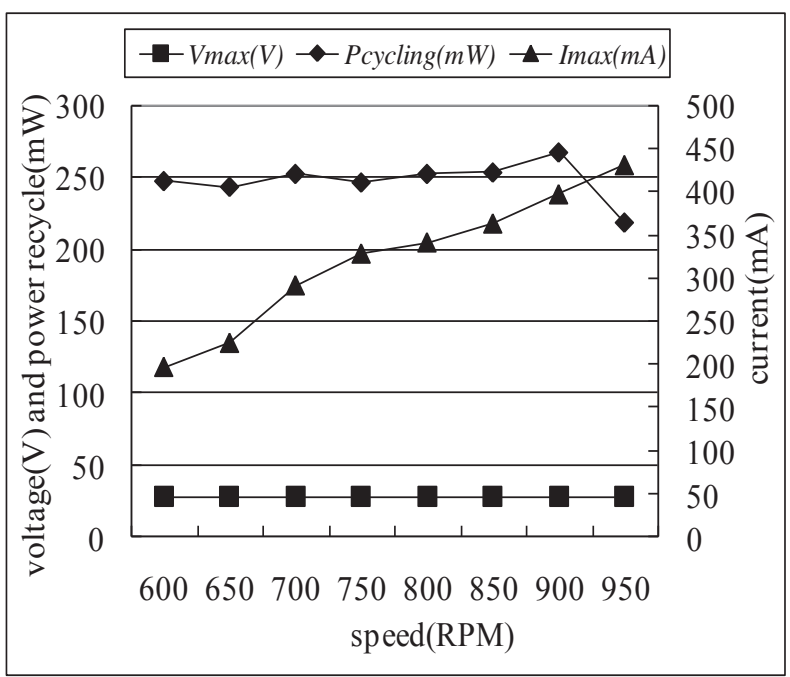

Fig.10. Energy recycle curve of with load and with energy collector of servo motor.

\subsection{Comparison of Energy Recovery of with load and without load of servo motor}

Comparison of the energy recycle of servo motor with or without energy collector and load as shown in table1, with the same speed, there is an average energy recovery of $251 \mathrm{~mW}$ with load and with energy collector more than the without load and without energy collector $120 \mathrm{~mW}$, and with load and with energy collector carrying the average power is without load and without energy collector more than 2 times.

Fig. 12 shows the comparison of the energy recovery power curve of the servo motor. At any speed, the recycling power of with load and with energy collector is higher than that of the without load and without energy collector. 
Table 1. Comparison of the energy recycles of the servo motor

\begin{tabular}{|c|c|c|}
\hline $\begin{array}{c}\text { speed } \\
(\mathrm{RPM})\end{array}$ & $\begin{array}{c}\text { Without load and } \\
\text { without energy } \\
\text { collector } \\
(\mathrm{mW})\end{array}$ & $\begin{array}{c}\text { With load and with } \\
\text { energy collector } \\
(\mathrm{mW})\end{array}$ \\
\hline 600 & 103 & 247 \\
\hline 700 & 141 & 243 \\
\hline 800 & 138 & 252 \\
\hline 900 & 114 & 246 \\
\hline 1000 & 104 & 252 \\
\hline 1100 & 113 & 253 \\
\hline 1200 & 124 & 267 \\
\hline average & 120 & 251 \\
\hline
\end{tabular}

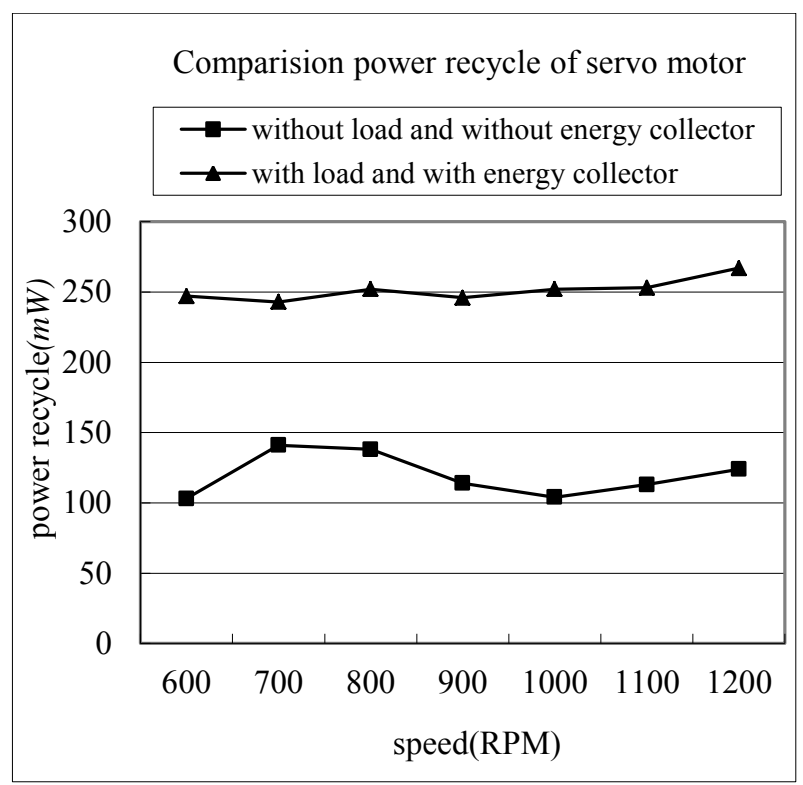

Fig.11. Comparison of the energy recycles of servo motor with or without energy collector and load.

\subsection{Energy recovery rate}

For the battery-driven power of the action of the vehicle, because the battery capacity can be used after the completion of the charge is determined, in accordance with the traditional use of methods, such as the reservoir in general, if no input, the reservoir will step by step pay and one day run out. For the battery-driven power of the action of the vehicle, because the battery capacity can be used after the completion of the charge is determined, in accordance with the traditional use of methods, such as the reservoir in general, if no input, the reservoir will step by step pay and one day run out. This article will use the energy consumption of the battery can be used so that the battery can increase the capacity to use and can lengthen its battery life, if used in mobile vehicles on its mileage will be lengthened with substantial application benefits.
Of course, the amount of recovery power, the capacity of the battery can be used and can lengthen its battery life; the recovery rate is also related to investment in economic benefits. The power recycle rate is calculated as shown in equations (3) and (4).

$$
\begin{aligned}
& P_{\text {in }}=V \times I \times T \\
& P R R=\frac{P_{\text {recycling }}}{P_{\text {in }}} \times 100 \%
\end{aligned}
$$

Where

$P_{i n}:$ input power

$V:$ input voltage

$I$ : input current

$T:$ peroid of power recycle

$P_{\text {recycling }}$ : power recycle of motor

$P R R$ : power recycle rate

Table 2 is power recycling of servo motor under without load and without energy collector, it can be seen that the maximum recovery power rate is $14.9 \%$ and the average energy recovery rate is $9.7 \%$.

Table 2. Power recycling of servo motor under without load and without energy collector.

\begin{tabular}{|c|c|c|c|c|c|}
\hline $\operatorname{Pin}(m W)$ & RPM & $V \max (V)$ & $\begin{array}{c}\text { Imax } \\
(m A)\end{array}$ & $\begin{array}{c}P \text { cycling } \\
(m W)\end{array}$ & $\begin{array}{c}P R R \\
(\%)\end{array}$ \\
\hline 0.78 & 600 & 21.3 & 96 & 103 & 14.9 \\
\hline 0.79 & 700 & 26.9 & 128 & 104 & 13.2 \\
\hline 0.88 & 800 & 27.2 & 222 & 110 & 12.6 \\
\hline 1.34 & 900 & 27.5 & 283 & 113 & 8.5 \\
\hline 1.46 & 1000 & 27.5 & 368 & 114 & 7.8 \\
\hline 1.62 & 1100 & 27.6 & 418 & 117 & 7.2 \\
\hline 1.75 & 1200 & 27.8 & 487 & 124 & 7.1 \\
\hline 1.98 & 1300 & 28.1 & 525 & 138 & 7.0 \\
\hline \multicolumn{3}{|c|}{ average $(\%)$} & & 9.8 \\
\hline
\end{tabular}

Table 3 is power recycling of servo motor under without load and with energy collector that the maximum recovery power rate is $33.59 \%$ and the average energy recovery rate is $10.7 \%$.

Table 4 is power recycling of servo motor under with load and without energy collector that the maximum recovery power rate is $2.7 \%$ and the average energy recovery rate is $1.8 \%$.

Table 5 is power recycling of servo motor under with load and with energy collector that the maximum recovery power rate is $4.0 \%$ and the average energy recovery rate is $3.1 \%$. 
Table 3. Power recycling of servo motor under without load and with energy collector.

\begin{tabular}{|c|c|c|c|c|c|}
\hline$P \operatorname{Pin}(m W)$ & RPM & $\operatorname{Vmax}(V)$ & $\begin{array}{c}\text { Imax } \\
(m A)\end{array}$ & $\begin{array}{c}P \text { cycling } \\
(m W)\end{array}$ & $\begin{array}{c}P R R \\
(\%)\end{array}$ \\
\hline 0.69 & 600 & 23.4 & 90 & 231 & 33.5 \\
\hline 0.79 & 700 & 25.3 & 102 & 240 & 30.5 \\
\hline 0.88 & 800 & 26.9 & 141 & 255 & 29.1 \\
\hline 1.34 & 900 & 26.9 & 150 & 237 & 17.7 \\
\hline 1.46 & 1000 & 27.5 & 206 & 226 & 15.5 \\
\hline 1.62 & 1100 & 27.2 & 288 & 232 & 14.3 \\
\hline 1.75 & 1200 & 27.8 & 338 & 226 & 12.9 \\
\hline 1.98 & 1300 & 27.5 & 438 & 213 & 10.7 \\
\hline \multicolumn{7}{|c|}{ average(\%) } & \multicolumn{5}{c}{20.5} \\
\hline
\end{tabular}

Table 4. Power recycling of servo motor under with load and without energy collector.

\begin{tabular}{|c|c|c|c|c|c|}
\hline $\operatorname{Pin}(m W)$ & RPM & $V \max (V)$ & $\begin{array}{l}\operatorname{Imax} \\
(m A)\end{array}$ & \begin{tabular}{|c|}
$\begin{array}{c}\text { Pcycling } \\
(\mathrm{mW})\end{array}$ \\
\end{tabular} & $\begin{array}{l}P R R \\
(\%)\end{array}$ \\
\hline 6.22 & 600 & 27.2 & 247 & 124 & 2.7 \\
\hline 6.64 & 650 & 27.5 & 291 & 134 & 2.4 \\
\hline 7.52 & 700 & 27.4 & 338 & 140 & 2.1 \\
\hline 8.05 & 750 & 27.5 & 381 & 142 & 1.8 \\
\hline 8.54 & 800 & 27.7 & 413 & 144 & 1.7 \\
\hline 9.38 & 850 & 27.8 & 444 & 147 & 1.4 \\
\hline 10.03 & 900 & 27.8 & 469 & 157 & 1.3 \\
\hline 11.15 & 950 & 27.8 & 488 & 161 & 1.3 \\
\hline \multicolumn{3}{|c|}{ Average $(\%)$} & \multicolumn{3}{|c|}{1.8} \\
\hline
\end{tabular}

Table 5. Power recycling of servo motor under with load and with energy collector.

\begin{tabular}{|c|c|c|c|c|c|}
\hline$P$ in $(m W)$ & RPM & $V \max (V)$ & $\begin{array}{c}\text { Imax } \\
(m A)\end{array}$ & $\begin{array}{c}\text { P cycling } \\
(m W)\end{array}$ & $\begin{array}{c}P R R \\
(\%)\end{array}$ \\
\hline 6.1 & 600 & 27.5 & 196 & 247 & 4.0 \\
\hline 6.6 & 650 & 27.5 & 224 & 243 & 3.7 \\
\hline 7.5 & 700 & 27.5 & 291 & 252 & 3.3 \\
\hline 8.1 & 750 & 27.8 & 328 & 246 & 3.1 \\
\hline 8.5 & 800 & 27.8 & 341 & 252 & 3.0 \\
\hline 9.0 & 850 & 27.5 & 363 & 253 & 2.8 \\
\hline 9.2 & 900 & 27.8 & 397 & 258 & 2.9 \\
\hline 10.4 & 950 & 27.8 & 431 & 235 & 2.1 \\
\hline \multicolumn{7}{|c|}{ average(\%) } & & 3.1 \\
\hline
\end{tabular}

Compare four cases of power recycle of servo motor. (1) Without load and without energy collector of average energy recycle is $9.7 \%$. (2) Without load and with energy collector of average energy recycle is $20.5 \%$. (3) With load and without energy collector of average energy recycle is $1.8 \%$. (4) With load and with energy collector of average energy recycle is $3.1 \%$.

\section{Conclusions}

Due to the electricity output by motor which not stable and the waveform in very short period appear to catch and regulate voltage in energy storage. It is through the chargeback controller to step up voltage and energy to battery. The recycle rate is inversely proportional to the speed and the maximum recycling current. If recycle rate is reduced which let the speed increasing and the maximum value of the recycling current becomes larger. And the recycling period is greatly reduced will made power recycle rate smaller.

In the case of energy recovery power; no matter how in load or without load that is a better energy recovery by the structure of with energy collector. From the view of recycle energy rate, the structure of the energy collector is better result.

\section{References}

1. M. Ortúzar, J. Moreno, and J. Dixon, "Ultracapacitorbased auxiliary energy system for an electric vehicle: implementation and evaluation," IEEE Trans. Ind. Electron, 54(4), 2147-2156, (2007)

2. Zhongyue Zou, Junyi Cao, Binggang Cao, Wen Chen. "Evaluation strategy of regenerative braking energy for supercapacitor vehicle," Is a Transactions, 55, 234-240, (2015)

3. Shuai Lu, K. A. Corzine, and M. Ferdowsi, "A new battery/ultracapacitor energy storage system design and its motor drive integration for hybrid electric vehicles," IEEE Trans. Veh. Technology. 56(4), 1516-1523, (2007)

4. J. Moreno, M. E. Ortúzar and J. W. Dixon, "Energymanagement system for a hybrid electric vehicle, using ultracapacitors and neural networks," IEEE Trans. Ind. Electron, 53(3), 614-623, (2006)

5. Chaofeng Pan, Liao Chen, Long Chen, Haobin Jiang, Zhongxing Li, Shaohua Wang. "Research on motor rotational speed measurement in regenerative braking system of electric vehicle," Mechanical Systems and Signal Processing, 66, 829-839, (2016)

6. Xiaohong Nian, Fei Peng, Hang Zhang, "Regenerative braking system of electric vehicle driven by brushless DC Motor," IEEE Transactions on Industrial Electronics, 61, 5798-5808, (2014)

7. Zhang Junzhi, Li Yutong, Lv Chen, Yuan Ye, "New regenerative braking control strategy for rear-driven electrified minivans," Energy Conversion and Management, 82, 135-145, (2014) 
8. S Lu, K/ Corzine, M Ferdowsi, " A New Battery/Ultracapacitor Energy Storage System Design and Its Motor Drive Integration for Hybrid Electric Vehicles," IEEE Transactions on Vehicular Technology, 56(4), 1516-1523, (2007)

9. J. Wang, B. Taylor, Z. G. Sun, and D. Howe, "Experimental characterization of a super capacitorbased electrical torque-boost system for downsized ICE vehicles," IEEE Trans. Vet. Technology, 56(6), 3674-3681, (2007)

10. Y. P. Yang and T. H. Hu. "A new energy management system of directly-driven electric vehicle with electronic gearshift and regenerative braking," in Proc., Amer. Contr. Conf., 4419-4424, (2007)

11. HM Huang, HJ Chiu, MH Tseng, LW Lin. "Design and implementation of a novel rapid charger with energy recovery," IEEE International Conference on Industrial Technology, 1300-1303, (2005) 